\title{
Of Making Many Books: A Library Publication Program
}

The paper discusses the need for and development of a library publication program. Details of organization, procedures, and personnel are discussed, the principles of which have broad application to other academic and research libraries.

$\mathrm{T}$ HERE IS MUCH to indicate that the current tendencies of libraries, especially research and special libraries, are to place a new importance on the mission of information storage and dissemination. Of course, information transfer has always been what libraries are about, but with the advent of automation more attention than ever before is being given to methods of getting the "warehouse" to the public in meaningful and digestible segments. Discussions of SDI, online and other automated services have blanketed the literature until it appears that not to be automated is to join forces with the library of Assurbanipal. Yet conventional publishing is far from obsolete. The research library has an even greater responsibility not only to provide access to its wealth of bookform data but, indeed, to assume an active role in purveying its unique resources to the research community and the reading public at large.

With this intent, in 1964 the Ohio State

Jo-Ann Davis is MEDLARS Searcher; Roberta Boone is Reference Librarian (Health Center Library); and Irene Braden Hoadley is Librarian for General Administration and Research at the Ohio State University Libraries.
University Libraries established a permanent Publications Committee, little realizing to what extent, and in what ways, this mission would be fulfilled.

The first meeting of the committee of five members (one ex-officio), appointed by the Director of Libraries, convened in October 1964. The functions and goals of the committee at that time were quite modest:

1. To assist and advise in matters pertaining to the Ohio State University Libraries' publications;

2 . to promote wider distribution of information;

3. to establish the criteria of selection for the Ohio State University collection (a special collection of publications about the Ohio State University or by its faculty members ).

Although the potential scope of these goals was clearly implied, little if any attention seems to have been paid to possible interpretations or implementations of the information dissemination aspect as such. The committee was, at this point, the classic house committee assigned to deal with the few house organs standard to a library's operations. Practically, the Libraries' publications, at that time, consisted of the usual exhibit catalogs, library guides, and annual re- 
port of the Director. However, with the advent of faculty status for librarians at Ohio State University and the concomitant interest of librarians in research, the responsibilities of the Publications Committee began to expand.

In 1967, the ex-officio member position was dropped from the committee and the remaining four membersdrawn from the Libraries' faculty-were appointed for renewable two-year terms. The mission of the committee was also extended, in 1968 , to include a research component. The committee is now charged with fostering and encouraging pertinent research by the Libraries' faculty or staff. To do this, the committee was given a small "seed" allocation and an independent account with the understanding that, through the sale of its products, it would become self-sustaining and able to sponsor additional projects of a scholarly nature worthy of publication.

In one year's time, the committee has become virtually self-sustaining. It has been allotted office space in the Libraries, keeps its own accounts and sales records, employs part-time clerical assistants and, in other words, has achieved that measure of autonomy so essential to the publishing arm of any organization. It even has its own colophon.

The committee, though working closely with the Director of Libraries, reports to the Libraries' faculty-at-large. In practical terms, this means that the chairman of the committee presents an annual report at the spring meeting of the $\mathrm{Li}$ braries' faculty, and any questions regarding the functioning of the committee or its operations may be answered at that time.

Thus far, several monographs, chiefly bibliographic, have been published either by the committee or under its auspices; an Ohio State University Libraries monographic series has been ini- tiated (consisting of four numbers to date); and, most recently, the committee now acts as publisher and distributor for a quarterly literary newsletter of which a member of the Libraries' faculty is co-editor. The committee is also involved, in cooperation with the Interlibrary Loan Department and the Dean of the Graduate School, in a project geared to the inexpensive publication of highly requested master's theses and doctoral dissertations completed before 1954. This activity occurred largely as a result of reports from Inter-library Loan that, in some cases, a cheaper, more readily available copy of certain items, unavailable elsewhere and hence in constant demand, would be of tremendous value to the researcher who otherwise would be forced to pay exorbitant photocopy charges to gain access to necessary information. When such an item is brought to the attention of the committee, the author is approached regarding his desire to have his thesis published in a more permanent form. If he assents, the department in which the thesis was submitted and the Dean of the Graduate School are informed and, with their approval, the thesis is edited, printed, and made available to the user at a fraction of the cost of photocopying.

Presently, the committee handles three types of publications: (1) conventional materials, such as exhibit catalogs and guides which are available on a gift and exchange basis; (2) the Libraries' numbered series which consists of substantive reference and bibliographic works; and (3) individual works for which there has been a demonstrated information need.

The committee is also charged generally with advising and assisting in the publication of manuscripts. Therefore, projects undertaken on the Libraries' time or with financial or other direct Libraries' support must be brought to the attention of the committee. Items 
which are published as official Libraries' publications must be submitted to the committee for consideration and approval.

When a manuscript is submitted, the committee determines the value of the item for publication. If an additional opinion is necessary for this determination, the committee will obtain the services of a subject specialist to assist in making the decision.

If the item is to be published, the committee then decides whether to publish it in house or to attempt to secure a commercial publisher. If the latter course is elected, the committee then seeks such a publisher and makes the necessary arrangements. The committee also determines whether the item will become part of the Libraries' numbered series.

If the manuscript is to be published in house, the committee provides clerical, editorial, or other assistance as necessary to prepare the final copy for publication. The committee also arranges for and subsidizes the cost for printing, advertising, sales, and distribution.

All monies derived from sales are placed in the committee's account to defray the costs of each publication. Excess funds are then used to finance new projects.

Each manuscript that is accepted by the committee is assigned to a committee member who acts as editor. This person edits and serves as a liaison between the author and the committee as a whole. Final action is always taken in consultation with the entire committee.

In order to handle the increased volume and variety of responsibility placed upon it, the committee has had to refine and streamline its structure and in house publication processes. Currently, each member is responsible for one functional aspect of committee operation. The first of these is printing and reproduction. The member responsible negotiates with the printer and advises on the method of printing and other technical considerations for each manuscript. All contact with the printer and university purchasing operations is done through this individual. The second aspect is publicity. This includes preparing mailing lists, press releases, displays, and advertisements for all committee activities. The member responsible for the third aspect (accounting and finance) maintains sales, inventory, and income records, the general files and records of the committee, and supervises the filling of all orders. The responsibilities of the chairman include coordinating the activities of the other members of the committee, keeping the minutes of meetings, interviewing and hiring personnel, drafting policy, procedures, and contracts for the committee, preparing statements and reports as needed, and arranging meetings and special activities.

The committee hands out to each prospective author a proof and manuscript guide (ours happens to be that published for The Association of American University Presses but there are other guides available) and a statement of the committee's manuscript requirements including such considerations as bibliographic style, type requirements, and author responsibilities, such as editing, proofing, and correction. The author/researcher is then assigned his committee liaison. When the manuscript is accepted for publication, an agreement is drawn up according to terms (sales, royalty, etc.) agreed upon by both the author and the committee. A Library of Congress number and copyright are then sought when appropriate, the cover design and book format are composed, and the manuscript is put out for bids and subsequently printed. At the same time, the nature and volume of publicity is determined, and decisions are made regarding review and other promotional aspects. 
Since the committee's formation, thirty-one publications have been done in house; fifteen of these within the last two years. Numerous items have been submitted to the committee for which a commercial publisher was subsequently found. These items currently assume such diversified forms as subject bibliographies, research monographs, and a poetry collection (for which an illustrator was also commissioned).

It should be obvious that one of the most valuable by-products of this activity is the wealth of experience gained by the professionals involved. A clearer understanding of what is involved in book production and of some of the basic criteria of book evaluation are substantial assets to the professional librarian. Twelve professional librarians have had the opportunity of serving and profiting from the experience.

But aside from the benefits accruing to the committee participants, is there good reason for the library to embark on an endeavor which only contributes to the proliferation of materials (and their equally proliferating storage and management problems) which are already a woe to the conscientious librarian?

Librarians have always been faced with the task of publishing their own in house necessities-material too ephemeral or too limited in appeal to attract a commercial publisher and material which must be disseminated quickly. From this type of publishing, it is but a small mental jump to publishing bibliographies, guides to the literature of various disciplines, or state-of-the-art reports. Nor is it difficult to envision libraries publishing material in the field of library science. What may be somewhat more incomprehensible is a library publishing materials completely unrelated to the library milieu (as unrelated as a book could be) such as a book on finance, a book of poetry, or a paper on computer-assisted instruction.
The rationale for library publishing is in part related to that for libraries themselves-to collect, organize, and disseminate information. Information dissemination has been defined as the spreading of ideas, but it has been suggested that libraries have taken too narrow an interpretation of this definition. Even now, with the many widespread attempts to instill new vigor into the word, most libraries still think of ideas as entities already existing in some physical, storable form-the forms with which a library deals. The ideas for which a patron searches however may not always be available in these cohesive permanent units. The library then is often the first agency to become aware of both the existence of a patron's need and the lack of availability of materials to fill that need. The demand for this data may be quite small or geographically limited or both. Most commercial publishers are often hesitant to take on small projects, and too often they already have a full publishing schedule so that it may take a considerable time to produce the finished product.

A library faculty may produce research which is worthwhile but which is also commercially unpublishable because of its small market. Thus, a library publication committee, while by no means a vanity press, serves as an outlet for the professional or creative work of library personnel and thereby stimulates professional research. The committee further encourages this research by publicizing current projects, by soliciting manuscripts to fill a specific need as perceived through library use, and by providing partial financial support.

The encouragement, support, and publication of research, based mainly upon a library's collections should be considered a forward-looking and important professional activity for a library. It is also a partial answer to the teaching 
faculty who often accuse librarians of not deserving faculty rank and status because they neither teach nor engage in research. Production of well-written professional and creative materials adds considerably to the prestige of a library. This prestige reflects upon the university as a whole and improves the library's position within the university community. It also reflects upon the profession as a whole, strengthens the library's power to attract new employees, and contributes to internal morale.

The above considerations are based on the premise that the library is publishing well-written, well-researched, and well-produced material. The library must build its reputation as publisher carefully, aiming at a small but specialized market whose needs it hopes to meet, while maintaining standards of excellence pertinent to its limited range of service.

To conclude, it should be pointed out that the establishment of a library publication program is not attained through a succession of sparkling accomplishments. The committee has waged many wars in pursuit of this goal.

It should be one of Murphy's laws that bureaucracy and human nature abhor change and individual accomplishment, especially in a large institution. There are always toes on which to tread or some legal conundrum designed to bring the cleverest notions to nothing.

There is the embarrassing situation of being able to get coverage in the national literature but being unable to procure adequate display facilities in one's own library lobby. There is also the frustration of having to clear press releases through so many administrative offices that the book has been out for two weeks before the notices leave the campus. This is not to mention the ulcerations of overestimates and underbids and the whole question of infringement and ownership when dealing with a manuscript produced as part of a university project (or when the author dies while his manuscript is still in the library's hands awaiting publication) and it is discovered that a division of a state institution cannot retain legal counsel. The "insolence of office and the law's delay" begins to appear the best-turned phrase in the English language. And through it all seep the insidious emanations from the academic departments who hate the program because it is "library," and from the administrative departments who hate it for raising new problems and more paperwork, and from the university press who hates it because it is competitive and anyhow, it is only "library."

But it is worth it precisely because of these pitfalls. If libraries have information to promote and are constantly searching for ways to accomplish this, why should they back away from a fullscale assault on the publishing medium as a means to that end? A whole noman's land of information resources-too small for the commercial press, too large for mimeograph or photocopy-is packed within the library's bulging walls. Dispense it! You have nothing to lose but the fetters on your image! 